Energy scavenging from insect flight

This article has been downloaded from IOPscience. Please scroll down to see the full text article.

2011 J. Micromech. Microeng. 21095016

(http://iopscience.iop.org/0960-1317/21/9/095016)

View the table of contents for this issue, or go to the journal homepage for more

Download details:

IP Address: 141.211.173.82

The article was downloaded on 06/04/2012 at 16:19

Please note that terms and conditions apply. 


\title{
Energy scavenging from insect flight
}

\author{
Ethem Erkan Aktakka $^{1}$, Hanseup Kim ${ }^{1,2}$ and Khalil Najafi ${ }^{1}$ \\ ${ }^{1}$ Department of Electrical Engineering and Computer Science, University of Michigan, Ann Arbor, \\ MI 48109, USA \\ ${ }^{2}$ Department of Electrical and Computer Engineering, University of Utah, Salt Lake City, \\ UT 84112-9206, USA \\ E-mail: aktakka@umich.edu
}

Received 21 April 2011, in final form 28 June 2011

Published 12 August 2011

Online at stacks.iop.org/JMM/21/095016

\begin{abstract}
This paper reports the design, fabrication and testing of an energy scavenger that generates power from the wing motion of a Green June Beetle (Cotinis nitida) during its tethered flight. The generator utilizes non-resonant piezoelectric bimorphs operated in the $d_{31}$ bending mode to convert mechanical vibrations of a beetle into electrical output. The available deflection, force, and power output from oscillatory movements at different locations on a beetle are measured with a meso-scale piezoelectric beam. This way, the optimum location to scavenge energy is determined, and up to $\sim 115 \mu \mathrm{W}$ total power is generated from body movements. Two initial generator prototypes were fabricated, mounted on a beetle, and harvested 11.5 and $7.5 \mu \mathrm{W}$ in device volumes of 11.0 and $5.6 \mathrm{~mm}^{3}$, respectively, from 85 to $100 \mathrm{~Hz}$ wing strokes during the beetle's tethered flight. A spiral generator was designed to maximize the power output by employing a compliant structure in a limited area. The necessary technology needed to fabricate this prototype was developed, including a process to machine high-aspect ratio devices from bulk piezoelectric substrates with minimum damage to the material using a femto-second laser. The fabricated lightweight spiral generators produced $18.5-22.5 \mu \mathrm{W}$ on a bench-top test setup mimicking beetles' wing strokes. Placing two generators (one on each wing) can result in more than $45 \mu \mathrm{W}$ of power per insect. A direct connection between the generator and the flight muscles of the insect is expected to increase the final power output by one order of magnitude.
\end{abstract}

(Some figures in this article are in colour only in the electronic version)

\section{Introduction}

Micro-air-vehicles (MAVs), flying robots the size of small insects, can create a new era for search-and-rescue operations, surveillance, monitoring of hazardous environments, and detection of explosives by taking advantage of their small size and the networked communication possible between multiple MAVs. Recent developments in actuation by smart materials and artificial muscles, and a better understanding of insect flight has enabled more effective design and modeling of MAVs, such as a biomimetic robotic fly [1], a passively stabilized machine for untethered flapping-hovering flight [2], a remote-controlled ornithopter [3], and a fully autonomous flight system for terrestrial and Mars surveys [4]. Other than the complex aerodynamics control and improved robustness to survive collisions, a common key challenge in the development of MAVs is the limited weight and volume reserved on the device for a long-life power source. Currently, all these MAV prototypes are either tested with an external power source, or have a maximum flight time of 5-10 min due to limited battery size.

Despite major recent advances in MAVs, no stateof-the-art micro vehicle offers superior flight mechanisms compared to the natural ones of insects. Insects' aerodynamic performance, incredible maneuvering capability, and the ability to lift payloads heavier than their body weights motivate researchers toward building hybrid insect vehicles (HIVs). It has been suggested that these cyborg insects be controlled via neural, optical or thermal stimulators, and possibly power the inserted microsystem by harvesting the insect's available mechanical, thermal or biological energy (figure 1). The hijacking of animal neural systems to build a locomotion control system has been studied in a variety of species previously. In the past decade, remote control of rats by implanted electrodes 


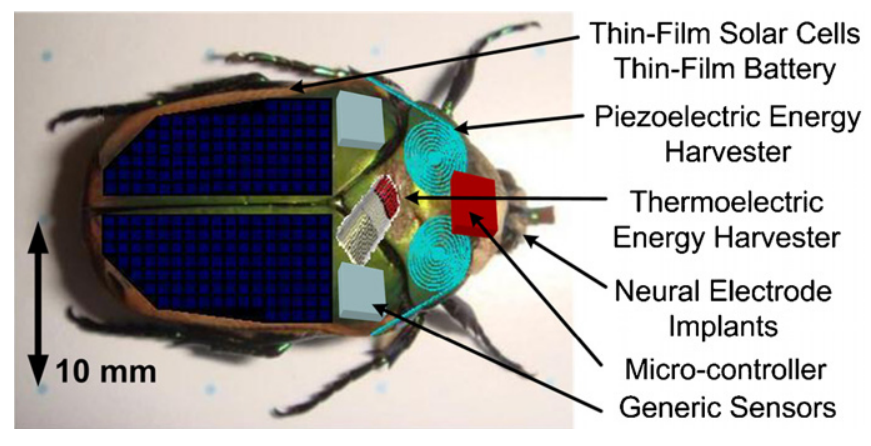

Figure 1. Graphical representation of a hybrid insect model, with the Green June Beetle chosen as the carrier insect.

in their brain centers related to their whiskers [5], stimulation of olfactory brain centers in sharks to control swim direction [6], wireless flight of pigeons [7], and locomotion control of cockroaches [8] have all been reported. In addition, more recently there has been great progress in the flight initiation and direction control of flying insects. Different approaches for flight stimulation include resistive/piezoelectric microthermal stimulators mounted near beetles' antennae [9], flexible multisite electrodes to interface with the central nervous system of moths [10], control of wing-beat frequency and amplitude in moths via neuromuscular interfaces [1113], and a tetherless implantable microsystem with brain and muscle stimulators for flight initiation/cessation and for direction control during flight [14].

Current HIV systems use batteries to power the microcontroller and muscle/neural stimulators, but the addition of an energy scavenging unit on the insect would provide an unlimited source of power over the insect's lifetime. The mission period would no longer be limited by the power source, and no additional maintenance would be required for recharging or replacing the battery. Capturing energy from sunlight via solar cells placed on the back of an insect is an attractive energy harvesting option. However, the delivered power would always be dependent on ambient light available in the environment, so it may not be feasible for certain missions. Alternatively, the necessary power can be supplied from the insects' own biological energy, such as by piezoelectric conversion of the high frequency body movements during flight $[15,16]$, and by thermoelectric conversion of body heat energy before and during flight [17]. Energy harvesting from mechanical movements of an insect is very promising in terms of both electrical output and applicability to the general insect world. An electromagnetic vibration energy harvester for hawk moths has been reported recently [18]; however, the device weight, $1.28 \mathrm{~g}$, was larger than the payload capacity of the insect, and the harvester operated only at a specific resonance frequency.

Previous literature indicates a range of wing beat frequencies within a single species, for example $15-28 \mathrm{~Hz}$ [19] and 24-32 Hz [20] for tobacco hawk moths. This is due to the inter-individual physiological differences affecting flight ability. Even the same individual insect changes its wing beat frequency during flight depending on environmental and physical conditions, such as temperature and humidity [21], or
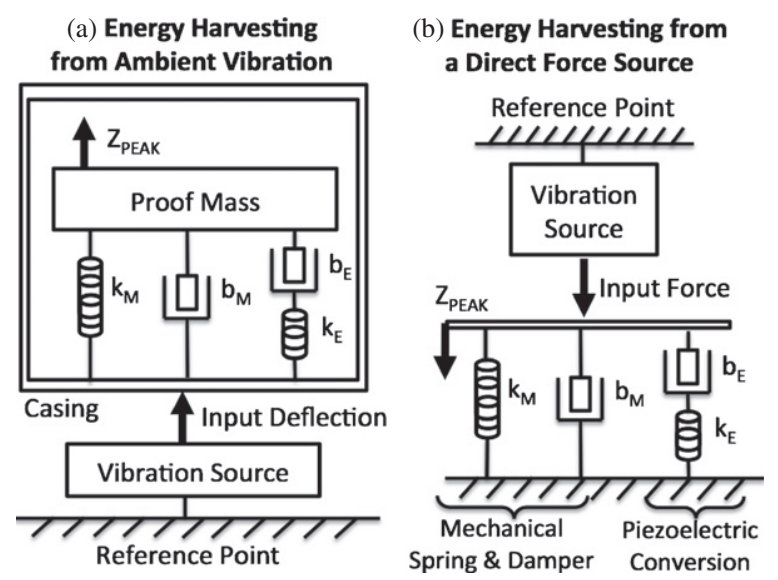

Figure 2. (a) Energy scavenging indirectly from ambient vibration and $(b)$ energy harvesting from a direct force source.

tiredness due to long flight duration [22]. Reconfiguration of a resonant device to match the changing flapping frequency is thus impractical unless there is an onboard active frequencytuning system, which could be energy-wise inefficient due to the consumed energy in the tuning mechanism.

This paper summarizes the first attempt to scavenge energy with non-resonant devices from live insects, specifically Cotinis nitida (Green June Beetle), an active day flyer with an average body mass of $1.3 \mathrm{~g}$, and average body size of $25 \mathrm{~mm} \times 15 \mathrm{~mm}$. An adult Cotinis nitida can convert its biochemical energy with $\sim 14.0 \%$ efficiency into a mechanical work of $8.6 \mathrm{~mW}$ in its flight muscles during its tethered flight [23]. A vibration energy scavenger might be able to convert $1-10 \%$ of this mechanical energy into electricity to power a hybrid-insect neuro-control system without disturbing the free flight of the beetle. In the following, the necessity of broadband energy harvesting from insect vibrations, and the theoretical considerations are presented in section 2. The optimum location to harvest vibration energy and available power output level from a flying beetle is outlined in section 3. Sections 4 and 5 discuss the design, fabrication and testing of cantilever beam and spiral beam piezoelectric energy harvesters. Performance comparison of the developed vibration energy harvesting system with other forms of available energy conversion methods is given in section 6 , including a brief discussion on how to further increase the power output in a conceptual design. Finally, conclusions about the study are drawn in section 7 .

\section{Theoretical considerations for energy scavenging}

\subsection{Resonant energy harvesting from ambient vibration}

It is beneficial to examine the different design considerations required for energy scavenging indirectly from ambient vibration (figure $2(a)$ ) versus directly from an attached vibration source (figure $2(b)$ ). In this study, piezoelectric energy conversion is chosen instead of electrostatic and electromagnetic alternatives, because of its advantages: a straightforward fabrication process, easier device miniaturization, favorable scaling of power as dimensions 
shrink, simple rectification/regulation circuitry due to the high voltage output compared to electromagnetic harvesters, and no necessity of charge-pump circuitry compared to electrostatic harvesters. Voltage output on a resistive load from a piezoelectric bimorph cantilever beam oscillating at an actuation frequency of $\omega_{\mathrm{ACT}}$ is given by $[24,25]$

$$
|V|=\frac{\omega_{\mathrm{ACT}} E_{P} d_{31} t_{P}}{\varepsilon \sqrt{\omega_{\mathrm{ACT}}^{2}+\frac{1}{\left(R C_{P}\right)^{2}}}} \cdot \delta_{\mathrm{AV}}(R),
$$

where $E_{P}$ is the Young's modulus, $d_{31}$ is transverse piezoelectric strain coefficient, $t_{P}$ is the piezoelectric layer thickness on each side, $\varepsilon$ is the dielectric constant, $C_{P}$ is the capacitance of piezoelectric layer and $R$ is the external resistive load. $\delta_{\mathrm{AV}}$ is the average strain in the piezoelectric layer, and it is a function of the electrical load, which determines the electrical damping on the beam and also changes the mechanical compliance of the piezoelectric layer [24]. For the case of ambient vibration, where there is a constant force acting at the tip of the beam, the deflection of the beam is determined by beam stiffness and damping. So, changing $R$ affects the tip deflection. On the other hand, for the case of a direct attachment of the tip of the beam to a strong vibration source, $Z_{\mathrm{PEAK}}$ is constant and externally supplied. Here, although increased beam stiffness due to different $R$ values requires a higher force from the source, the input displacement is assumed to stay constant. In this case, the resistive load only affects the electrical power transfer not the mechanical motion, and $R$ is optimum at $1 /\left(\omega_{\mathrm{ACT}} . C_{P}\right)$ for maximum electrical power transfer. For the sake of simplicity, the same optimum value will be assumed for the case of ambient vibration too. Using maximum tip deflection $\left(Z_{\mathrm{PEAK}}\right)$ instead of average strain in the piezoelectric layer $\left(\delta_{\mathrm{AV}}\right)$ in equation (1) reveals the harvested electrical power from the beam as

Power $=\frac{V_{\mathrm{RMS}}^{2}}{R_{\mathrm{LOAD}}}=\frac{9}{64} \cdot \frac{E_{P} d_{31}^{2}}{\varepsilon} \cdot \frac{1}{4} E_{P} \frac{W T^{3}}{L^{3}} \cdot \omega_{\mathrm{ACT}} \cdot Z_{\mathrm{PEAK}}^{2}$,

where $L$ is the beam length, $W$ is the beam width and $T$ is the total thickness. In an ambient vibration, the tip deflection is determined by the input acceleration and frequency:

$$
Z_{\text {PEAK }}=\frac{A}{\omega_{\text {ACT }}^{2}} \cdot \theta,
$$

where $\theta$ is a unitless parameter, which depends on the total damping factor $(\xi)$ :

$$
\theta=\frac{\omega_{N}^{2}}{\sqrt{\left(\omega_{N}^{2}-\omega_{\mathrm{ACT}}^{2}\right)^{2}+\left(2 \xi \omega_{N} \omega_{\mathrm{ACT}}\right)^{2}}} .
$$

Average power output from a piezoelectric bimorph cantilever beam oscillating due to ambient vibration can be derived from (2), by replacing $Z_{\text {PEAK }}$ with acceleration input $A$, and the dimensional parameters with beam's resonance frequency $\omega_{N}$ :

Power $_{\text {Ambient-Vibration }}=\frac{9}{64} \cdot \frac{E_{P} d_{31}^{2}}{\varepsilon} \cdot m_{\mathrm{EFF}} \cdot \omega_{\mathrm{ACT}} \cdot \frac{A^{2}}{\omega_{N}^{2}} \cdot \theta^{2}$.

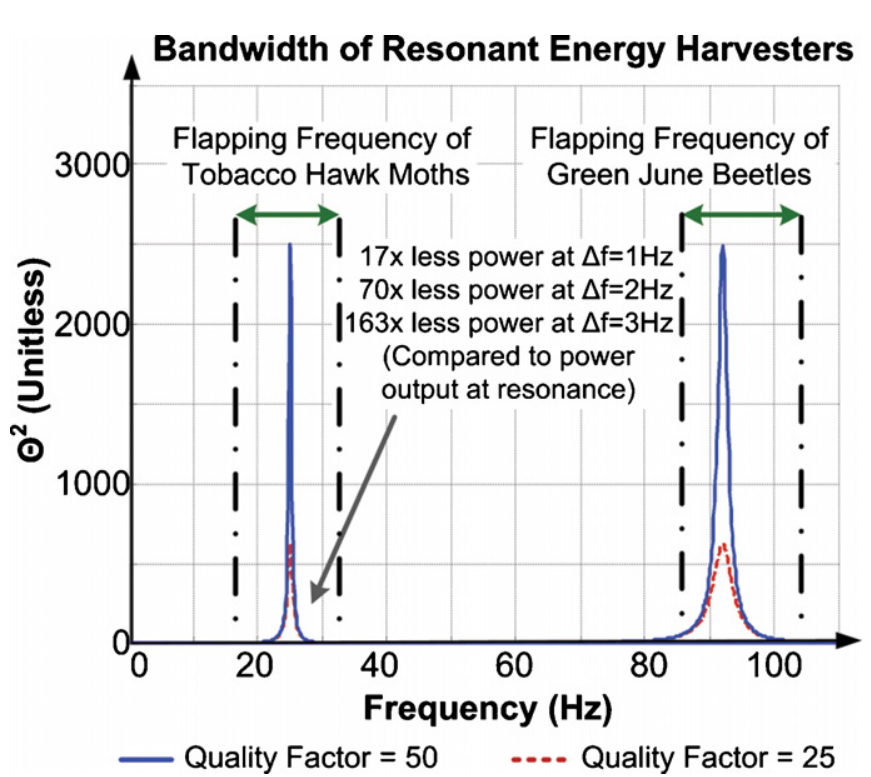

Figure 3. Bandwidths of typical resonant energy harvesters with modest quality factors.

In order to maximize Power/Volume, a designer should maximize the effective mass $\left(m_{\mathrm{EFF}}\right)$ acting at the tip of the beam in a restricted device volume, use a piezoelectric material with a high coupling coefficient, and target a low frequency vibration source due to its high-energy density for the same acceleration input. For a fixed proof mass, one needs to adjust the spring constant to match the resonance frequency of the device with the actuation frequency $\left(k_{\mathrm{SPRING}}=m_{\mathrm{EFF}} \cdot \omega_{N}{ }^{2}\right)$. When $\omega_{N}$ and $\omega_{\mathrm{ACT}}$ match, $\theta$ reaches its maximum value, equal to the mechanical quality factor of the system $(Q=1 / 2 \xi)$. For higher power output at resonance, the quality factor can be increased by minimizing air and material damping; however, this will also cause a decrease in the bandwidth of the energy harvester $\left(\Delta \omega=\omega_{N} / Q\right)$. In resonant energy harvesting, if $\omega_{N}$ and $\omega_{\mathrm{ACT}}$ do not match exactly, the output power can be orders of magnitude lower than the maximum power output obtained at resonance. In our target application, the flapping frequency of an insect is not constant for different individuals in the same species or even for the same individual under different conditions. Therefore, a resonant device is not a practical solution for broadband energy harvesting from insects (figure 3).

\subsection{Non-resonant energy harvesting from a direct force source}

Equation (2) can be interpreted for energy scavenging from an external force source directly actuating the tip of a bimorph cantilever beam:

$$
\text { Power }_{\text {Direct-Force }}=\frac{9}{64} \cdot \frac{E_{P} d_{31}^{2}}{\varepsilon} \cdot \omega_{\mathrm{ACT}} \cdot k_{\mathrm{SPRING}} \cdot Z_{\mathrm{PEAK}}^{2} \cdot
$$

Now, since an external force source provides a constant deflection on the beam, there is no need to have a proof mass at the tip of the beam, resulting in a much lighter design in terms of weight. Instead, the spring constant should be kept as 


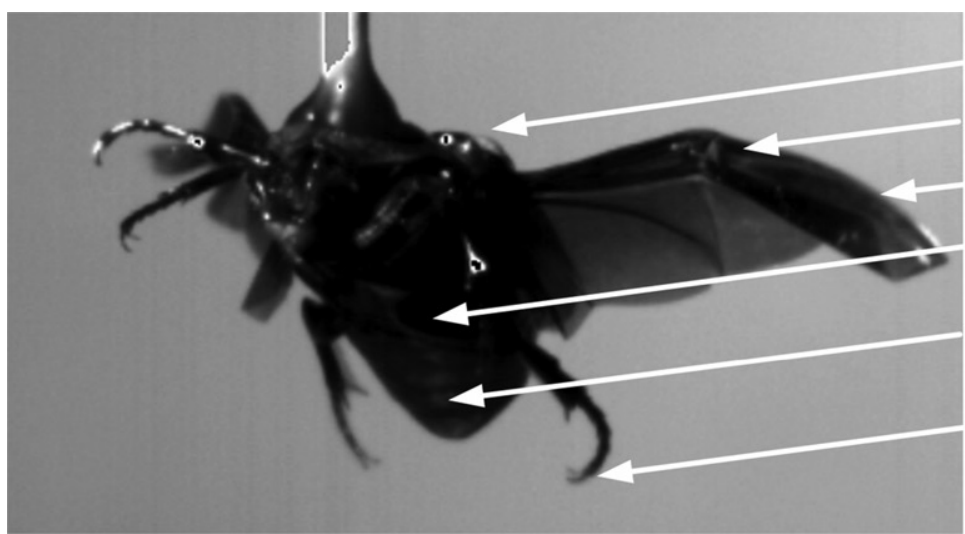

$\begin{aligned} & \text { Anterior Elytra Section } \\ & \text { (Hardened Wing Cover) }\end{aligned}$
Last rigid point on wing
Membranous wing tip
Ventral Abdomen Section
Posterior Abdomen Section
$\quad$ Start/End of Flight
$\quad$ In flight
Hind Leg
Middle Leg
Fore Leg

$0.8 \mathrm{~mm}_{\mathrm{PP}}$ at $\sim 92 \mathrm{~Hz}$

$7 \mathrm{~mm}$ pp at $\sim 92 \mathrm{~Hz}$

$8 \mathrm{~mm}$ pp at $\sim 92 \mathrm{~Hz}$

$2 \mathrm{~mm}_{\mathrm{pp}}$ at $\sim 92 \mathrm{~Hz}$

3-6 $\mathrm{mm}_{\mathrm{pp}}$ at $\sim 1 \mathrm{~Hz}$

$0.5 \mathrm{~mm}_{\mathrm{pp}}$ at $\sim 92 \mathrm{~Hz}$

$15-20 \mathrm{~mm}$ pp (not periodic)

$15-20 m_{P P}$ (not periodic)

$10-12 \mathrm{~mm}$ PP (not periodic)

Figure 4. Deflection and frequency measurements (with a high-speed camera) on a beetle during its tethered flight.

high as possible in order to maximize the coupled force input into the system. Of course, the input force on the scavenger should still be below of the available force at the source, and thus not restrict the free deflection of the source. In practice, in our case, this defines a maximum value of $k_{\text {SPRING }}$, and this design limit is determined by the disturbance of free flight and physical exhaustion of the insect. In addition, now there is no need to match $\omega_{N}$ and $\omega_{\mathrm{ACT}}$ or to have a high $Q$ system for higher power output, since the beam deflection is constant and independent of $\theta$. Still, matching actuation and resonance frequencies could be beneficial to decrease the necessary input force from the source, i.e. to reduce the mechanical load to the insect, but only in a narrow bandwidth.

In equation (6), $k_{\text {SPRING }} \times Z_{\text {PEAK }}$ actually denotes $F_{\text {PEAK }}$, the input force acting on the piezoelectric beam, so when scavenging energy directly from a vibration source, the scavenged energy is proportional to frequency $\times$ force $\times$ deflection available from the source. Thus, in order to define the best location for energy scavenging and to have an idea of possible power output, several measurements were performed during tethered flight of a subject beetle.

\section{Determining optimum location to scavenge energy from a flying insect}

Acoustic measurements are used to define the average fundamental wing-stroke frequency, $92.1 \mathrm{~Hz}$. During these measurements, it has been observed that start-up and end portions of a flight give smaller flapping frequency than the average, and additionally flapping frequency may decrease over time as the subject beetle gets tired. A range of $85-105 \mathrm{~Hz}$ flapping frequency is recorded from different individual beetles. This wide range can be explained with the previous literature [26]: the flapping frequency depends on many conditions such as body mass, oxygen concentration in the environment, ambient temperature, thoracic temperature, ambient light and feeding nutrition.

Deflection and frequency of movements at various body sections are measured with high speed (6000 fps) camera recordings (figure 4). With the results of these measurements, one might presuppose that scavenging energy from wing tip displacement can provide maximum power output, since the

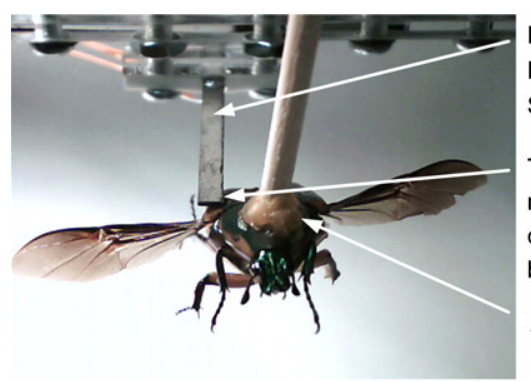

Piezoelectric Cantilever Beam Resonance freq. $=423 \mathrm{~Hz}$ Spring constant $=407 \mathrm{mN} / \mathrm{mm}$

The tip of the piezoelectric macro-scale beam is held at different vibrating sections of a beetle during its tethered flight.

A wax droplet is used to stabilize the beetle in position

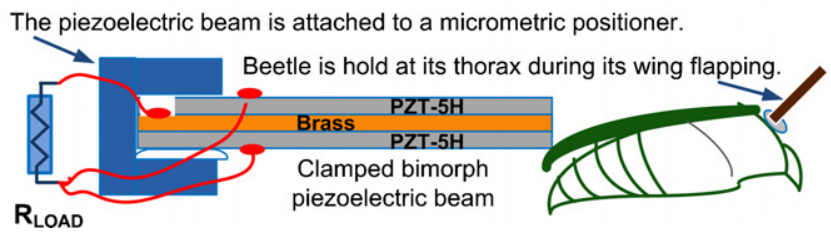

Figure 5. Setup used to measure available power from various body parts of a beetle during its tethered flight.

wing tip has the highest amplitude of periodic deflection compared to other body parts. However, the membranous wing is not rigid and strong enough to hold and actuate a generator, and thus the output force and energy from this body movement is limited. Moreover, a mechanism built at this location can prevent wing-folding over abdomen during beetle's resting time, and also cause aerodynamic disadvantages during flight. Similarly, scavenging energy from leg movements and abdomen vibration is not very promising in terms of power output, as oscillations are usually not periodic nor high frequency.

In order to define available force and power output from a beetle's movements at various locations of its body, a setup is built using a meso-scale piezoelectric bimorph beam (figure 5). The beam is formed of two $130 \mu \mathrm{m}$ thick seriespoled PZT-5H layers with a $130 \mu \mathrm{m}$ thick brass shim layer in-between. The piezoelectric beam is fixed at one end to a micrometric positioner, and the free tip of the beam is held over various vibrating parts of the body during the beetle's tethered flight.

In this experiment and for the fabrication of following prototypes, PZT is the chosen piezoelectric material due to its high electromechanical conversion efficiency compared 
Output of Macro Scale Piezoelectric Beam on $35.5 \mathrm{k} \Omega$ at Optimum Location on Beetle (V)

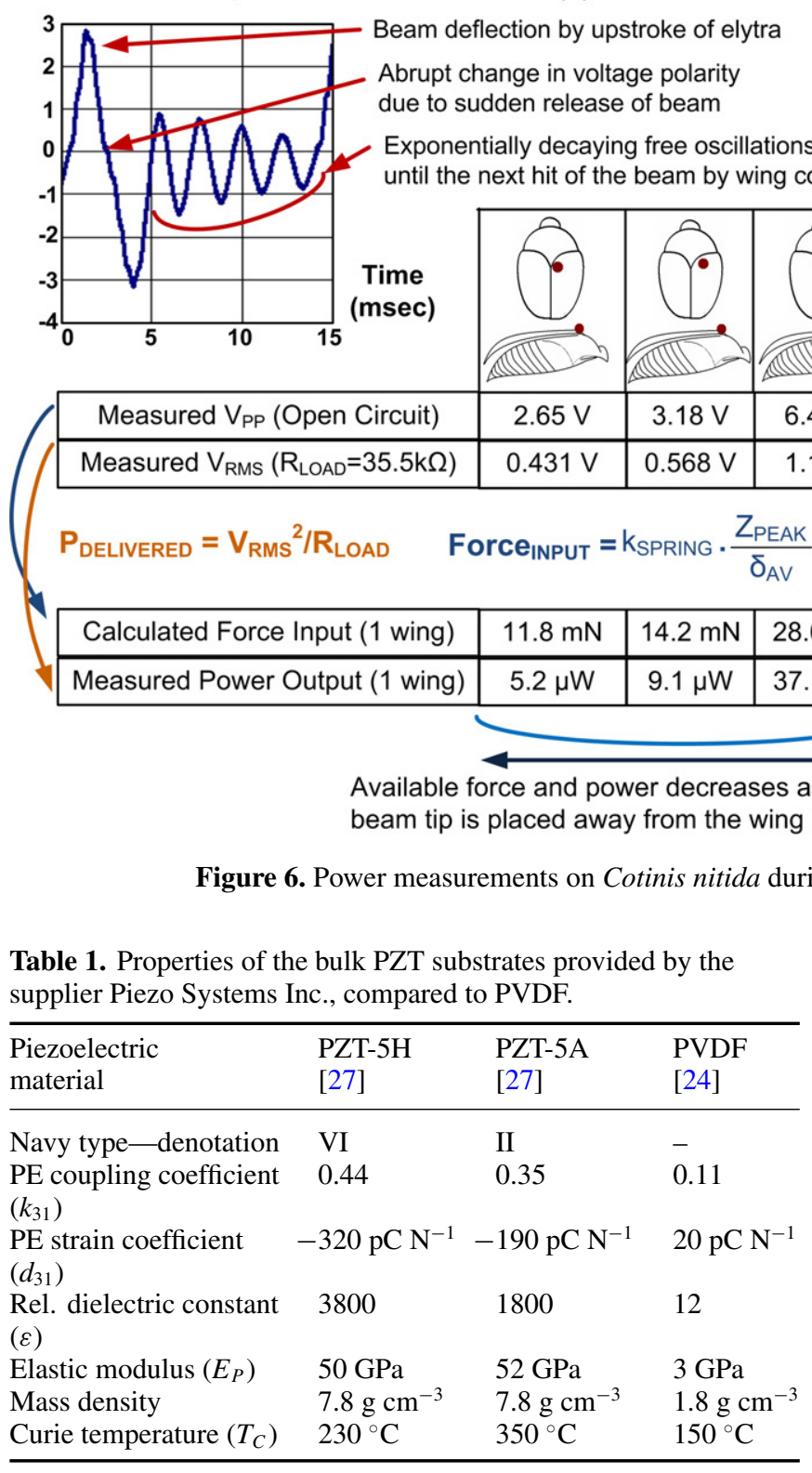

to other material options. The properties of the bulk piezoelectric substrates used in this experiment (PZT-5H) and in the fabrication of cantilever beam prototypes (PZT-5H) and spiral beam prototypes (PZT-5A) are summarized in table 1. Although PVDF can be preferred as an alternative to PZT in sensor applications where beam flexibility is more important than the piezoelectric coupling, for energy harvesting it would result in an order of magnitude lower power output due to its lower $k_{31}^{2}$ value.

The open circuit voltage output of the piezoelectric beam is used to calculate the maximum input force acting on the beam, whereas the output voltage on an optimum resistive load of $35.5 \mathrm{k} \Omega$ is used to calculate average electrical power available from this motion. In these experimental measurements (figure 6), both input mechanical force from the beetle and electrical power output increased as the measurement spot moved toward the flight muscle base. This result concurs with our intuition that it is best to scavenge energy as close as possible to the source of vibration. From two wings, $115 \mu \mathrm{W}$ total power generation is demonstrated due to elytra vibration close to the wing base (the elytra is the hardened forewing covering and protecting the membranous hindwing), where both peak force input $(35 \mathrm{mN}-40 \mathrm{mN})$ and oscillatory displacement $\left(0.8 \mathrm{~mm}_{\mathrm{PP}}\right)$ are considerably large.

\section{Cantilever beam energy harvester prototypes}

Two initial backpack-type energy scavenger prototypes (figure 7) were fabricated from $380 \mu \mathrm{m}$ thick PZT$5 \mathrm{H} /$ brass/PZT-5H bimorphs, then mounted on beetles and tested during their tethered flight. The flights were initiated by external light and heat stimulation. Prototype-I, stretching from thorax to far abdominal end of elytra, delivered $874 \mathrm{mV}_{\mathrm{RMS}}$ to a $66.6 \mathrm{k} \Omega$ load. This corresponds to $11.5 \mu \mathrm{W}$ power generation in a total device volume of $11.0 \mathrm{~mm}^{3}$.

Prototype-II is formed of two short piezoelectric beams with their fixed end mounted on the thorax, and vibrating tips standing freely over the wing base on each side. The beams are actuated upward by left and right elytra upstrokes during flight, and then experience a decaying oscillation back to their original zero-deflection positions at their resonance frequency until they are hit back again by the elytra. This prototype generated $7.5 \mu \mathrm{W}$ in a device volume of $5.6 \mathrm{~mm}^{3}$. Simultaneously recorded outputs from right and left piezoelectric beams can be seen in figure 8 . The advantage of this prototype compared to the first one is that it was placed closer to the vibration source and hit by a higher force source. 


\section{Cantilever Beam Prototype-I}

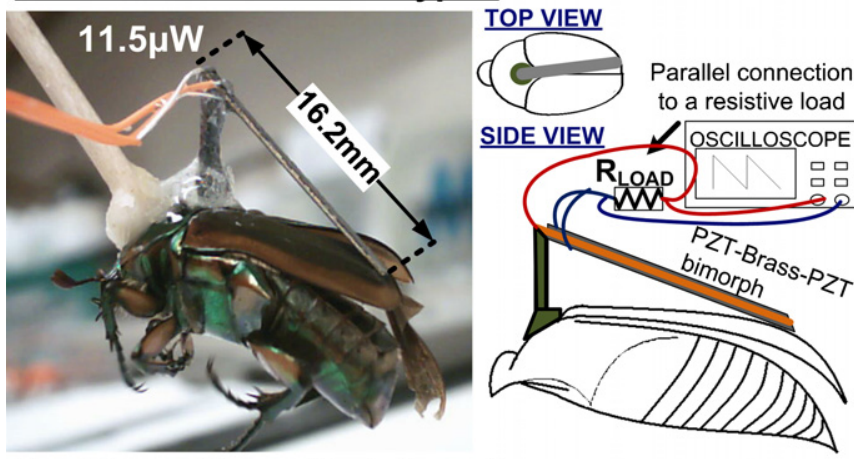

\section{Cantilever Beam Prototype-II}

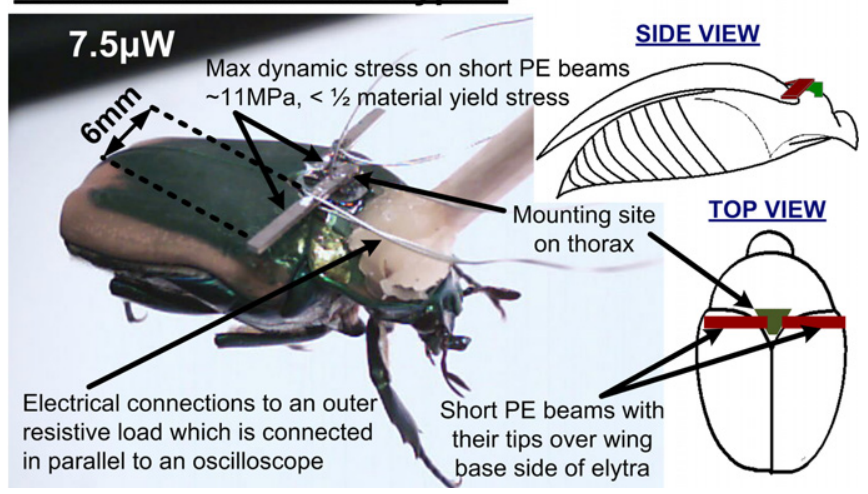

Figure 7. Prototype-I and prototype-II mounted on subject beetle.

Table 2. Performance summary of cantilever beam energy scavengers prototype-I and prototype-II.

\begin{tabular}{|c|c|c|}
\hline $\begin{array}{l}\text { Generator } \\
\text { parameters }\end{array}$ & $\begin{array}{l}\text { Cantilever } \\
\text { prototype-I }\end{array}$ & $\begin{array}{l}\text { Cantilever } \\
\text { prototype-II }\end{array}$ \\
\hline \multicolumn{3}{|c|}{ Device specs } \\
\hline Natural frequency & $680 \mathrm{~Hz}$ & $5000 \mathrm{~Hz}$ \\
\hline Spring constant (Calc.) & $309 \mathrm{mN} \mathrm{mm}^{-1}$ & $3700 \mathrm{mN} \mathrm{mm}^{-1}$ \\
\hline $\begin{array}{l}\text { Force input from insect } \\
\text { (Calculated) }\end{array}$ & $17 \mathrm{mN}$ & $40 \mathrm{mN}$ \\
\hline Device volume & $11.0 \mathrm{~mm}^{3}$ & $5.6 \mathrm{~mm}^{3}$ \\
\hline Device weight & $86.5 \mathrm{mg}$ & $44 \mathrm{mg}$ \\
\hline \multicolumn{3}{|c|}{ Test results } \\
\hline Total power output & $11.5 \mu \mathrm{W}$ & $7.5 \mu \mathrm{W}$ \\
\hline Optimum $R_{\mathrm{LOAD}}$ & $66.6 \mathrm{k} \Omega$ & $200 \mathrm{k} \Omega$ \\
\hline $\mathrm{V}_{\mathrm{RMS}}\left(\right.$ on $\left.R_{\mathrm{LOAD}}\right)$ & $875 \mathrm{mV}$ & $772-945 \mathrm{mV}$ \\
\hline $\mathrm{V}_{\mathrm{PP}}($ Open circuit $)$ & $6.56 \mathrm{~V}$ & $6.60-8.28 \mathrm{~V}$ \\
\hline Power/device volume & $1.05 \mathrm{~mW} \mathrm{~cm}^{-3}$ & $1.34 \mathrm{~mW} \mathrm{~cm}^{-3}$ \\
\hline Power/device weight & $133 \mu \mathrm{W} \mathrm{g}^{-1}$ & $170 \mu \mathrm{W} \mathrm{g}^{-1}$ \\
\hline
\end{tabular}

Thus, a higher power density (Power/Weight) of $170 \mu \mathrm{W}$ $\mathrm{g}^{-1}$ is obtained, compared to the first prototype that achieved $133 \mu \mathrm{W} \mathrm{g}^{-1}$ (table 2).

As mentioned earlier, the spring constant of a piezoelectric beam to be attached to the insect is limited by $k_{\mathrm{MAX}}$ at the actuation region (the maximum force provided by insect divided by the displacement of the body part). This value can be calculated as $90 \mathrm{mN} \mathrm{mm}{ }^{-1}$ for vibration of elytra close to the wing base. Since these initial prototypes had high beam stiffness, their vibrating tips could not be attached directly to the elytra without limiting wing folding/unfolding movements, preventing initiation of flight or causing
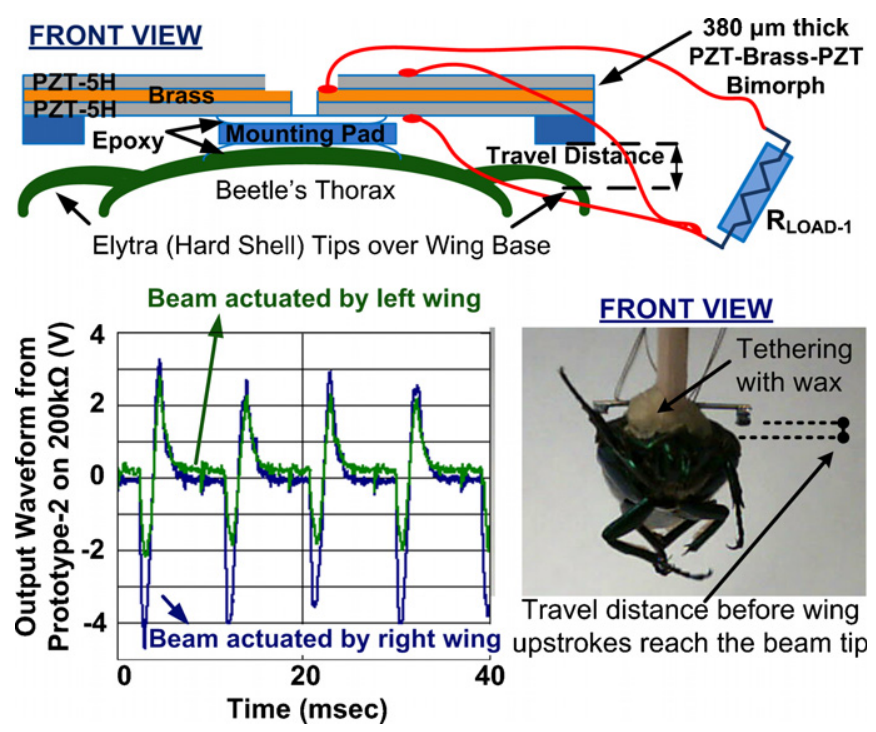

Figure 8. Simultaneous outputs generated by two PE beams of prototype-II.

disturbance of free flight aerodynamics. Therefore, a gap between the device tip and the actuation site was provided. However, with this configuration the generator cannot take advantage of full-span deflection of the elytra. So, although the value of $k_{\text {SPRING }}$ is higher, $Z_{\text {PEAK }}$ decreases considerably, reducing the harvested power. Since our aim is to harvest maximum electrical power with minimum exhaustion of the insect, the efficiency of mechanical energy coupling into the system should be maximized via direct attachment of the generator to the vibration source. This requires a lower spring constant design. Another design constraint for the final prototype is to avoid cracks or fatigue in the material caused by operation, so the maximum beam stress should be kept lower than dynamic yield strength of PZT ( $\sim 25 \mathrm{MPa})$.

\section{Spiral beam energy harvester prototypes}

\subsection{Design of the piezoelectric spiral beams}

As the available area for an energy scavenger mounted on an insect is limited, it is hard to build a device that both has the right spring constant and has maximum active material volume to generate as much power as possible. Thinning the PZT cantilever beam down to $<30 \mu \mathrm{m}$ total thickness is a possible way to allow the required high deflection $\left(0.8 \mathrm{~mm}_{\mathrm{PP}}\right)$ on an $8 \mathrm{~mm}$ long beam, while keeping the maximum dynamic stress less than yield strength. However, in this case the spring constant would be so low that the piezoelectric beam would only use $\sim 1 / 10$ th of the available force input from the insect. (For increasing the spring constant, the beam width can only be adjusted up to $\sim 6 \mathrm{~mm}$ due to the area limitation.) This means only $1 / 10$ th of the available mechanical energy would be harvested. Additionally, the required silicon based fabrication process would be more complex and costly compared to patterning of a commercially available bulk PZT bimorph substrate.

To overcome this design obstacle, the final energy scavenger prototype (figure 9) was designed by employing 


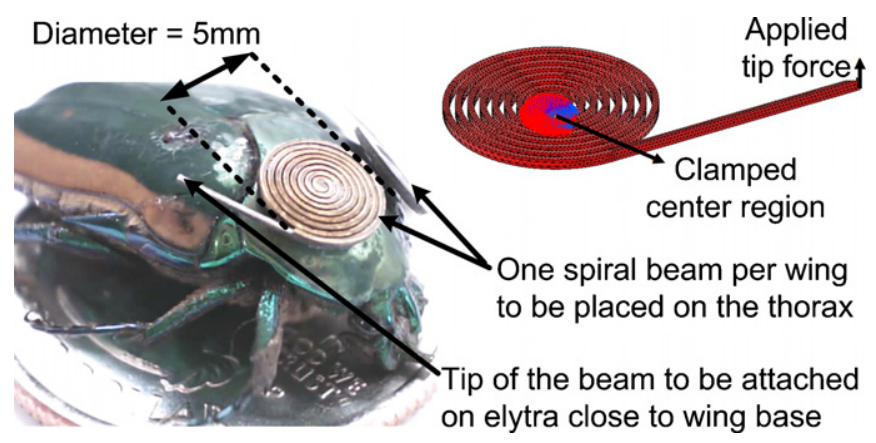

Figure 9. Final prototype; conceptual device geometry constrained in a $5 \mathrm{~mm} \times 5 \mathrm{~mm}$ area, and device placement on a beetle's dorsal thorax.

a spiral beam geometry that can occupy a limited area $(6 \mathrm{~mm} \times 6 \mathrm{~mm})$. With these dimensions, two spiral beams can be placed on thorax of a beetle, with their center region fixed, and the vibrating tips attached to the flapping elytra over wing base on each side. The device dimensions (number of turns, width of the beam, distance between turns. etc) are optimized to maximize the strain formed on the piezoelectric layer upon rated deflection of elytra, and thus maximize the power generation.

During multi-physics FEA simulations (ANSYS v.12.1) of the spiral, it has been observed that the nodal charge distribution is not uniform across the top and bottom electrode layers when a static force is applied to the tip of the beam. The polarity of produced charge in one layer (either top or bottom) changes across the zero-strain, zero-charge axis, which passes through the center of the clamped region and the tip of the beam (figure 10). Thus, a single electrode covering the top or bottom surface would cause charge cancellation, and produce a minimum amount of output voltage. In order to avoid charge cancellation, the two sides of the zero-charge axis can be polarized in opposite directions. Simulations indicate that an input force of $<30 \mathrm{mN}$ is required for $0.8 \mathrm{~mm}_{\mathrm{pp}}$ actuation of this design, and that $20-25 \mu \mathrm{W}$ can be generated per device at the insect's flapping frequency and elytra deflection. Placement of two spiral generators, one per wing, can provide a total output of $\sim 50 \mu \mathrm{W}$, which is close to the worst case power consumption $(80 \mu \mathrm{W})$ of the wing muscle neural stimulator used in [10] for direction control during flight.

\subsection{Fabrication of the piezoelectric spiral beams}

The spiral generators are fabricated from commercially available $380 \mu \mathrm{m}$ thick PZT-5A/brass/PZT-5A bimorph plates. The metal shim layer at the center is used both to provide structural strength to the final device, and also to constrain the piezoelectric charge at the top layer. Additionally, this metal layer keeps the PZT layers in compressive stress due to thermal expansion mismatch between PZT and brass. This compressive stress is favorable for larger operational dynamic range and device reliability, since the compressive strength of PZT is 5-10 times higher than its tensile strength.

Variable-zone polarization has been performed to avoid charge cancellation in the spiral structure as described above. (a) Nodal voltage output with uniform polarization across the piezoelectric device (No surface electrode)

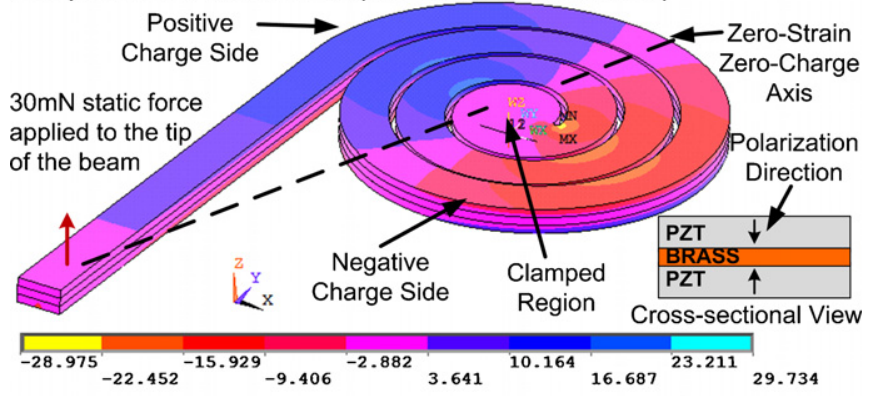

(b) Electrode output with uniform polarization

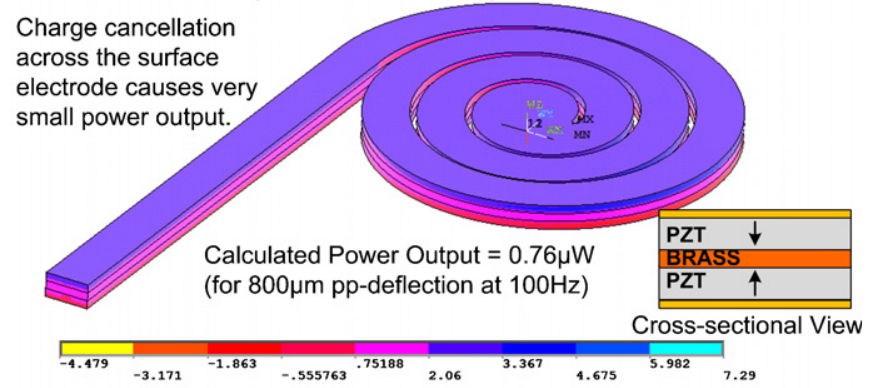

(c) Electrode voltage with variable-zone polarization

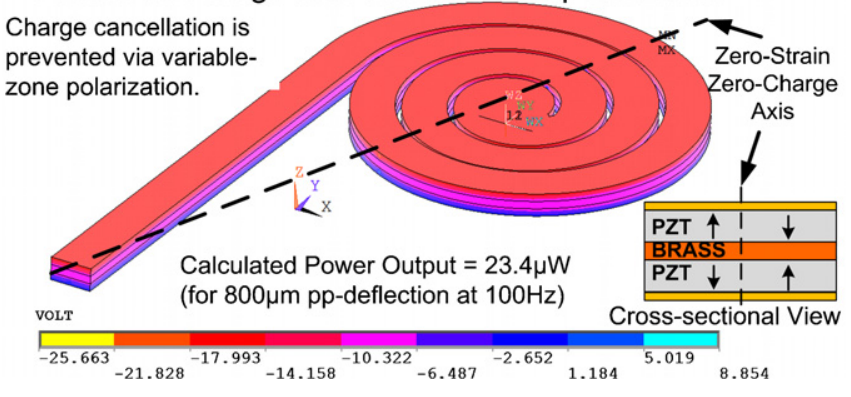

Figure 10. Charge cancellation in a uniformly polarized spiral beam can be prevented by variable-zone polarization.

The bimorph plate was first coated with patterned metals, then re-polarized on a hot-plate $\left(100{ }^{\circ} \mathrm{C}\right)$, and finally electrically re-connected on both sides by filling the separation gaps with sputtered $\mathrm{Cr} / \mathrm{Au}$ to short the whole electrode layer on the surface (figure 11).

In order to cut the spiral shape, high aspect ratio patterning of bulk PZT has been developed using a Ti-Sapphire femtosecond laser $(\lambda=780 \mathrm{~nm})$ with $150 \mathrm{fs}$ pulse duration and $1 \mathrm{kHz}$ repetition rate. Compared to previous technologies, such as reactive-ion etching (RIE), milling, ultrasonic machining and nanosecond laser ablation, the femto-second laser requires a relatively short etch time and minimizes mechanical and thermal damage that can degrade piezoelectric properties. In the laser micro-machining setup, a photonic crystal and a polarizer is used to adjust the laser power level, while an air flow is created on the focal point to decrease the debris formation on the sample. The complex spiral patterning is achieved by moving the sample via a programmable stage with four degrees-of-freedom. Laser fluence (= laser power/spot size) and linear scan speed along the pattern trajectory are optimized to minimize damage to the material, while the 


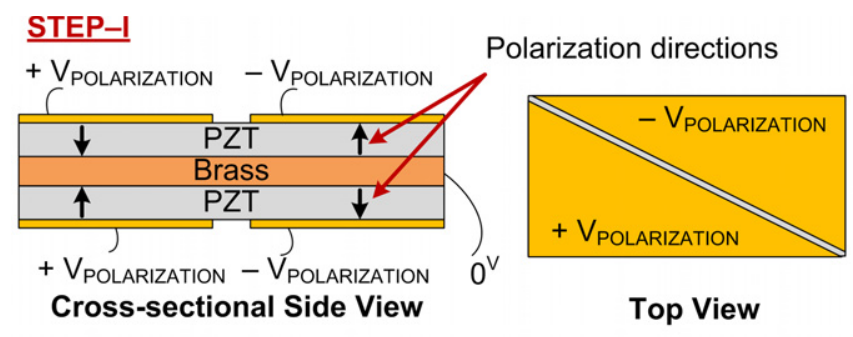

1-) Aligned electrode patterning on 2 sides of a bimorph sample. 2-) Variable-Zone Polarization of PZT layers with $+/-2000 \mathrm{~V} / \mathrm{mm}$.

\section{STEP-II}

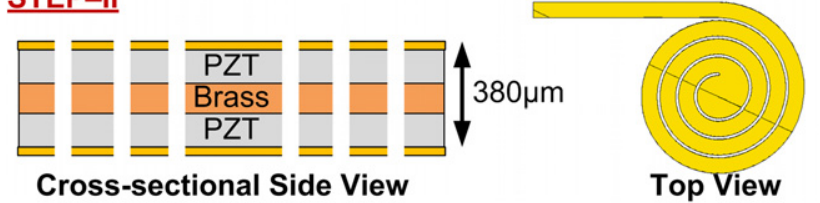

3-) Conformal metallization to reconnect the surface electrodes.

4-) Femto-second laser micromachining of bimorph spiral beam.

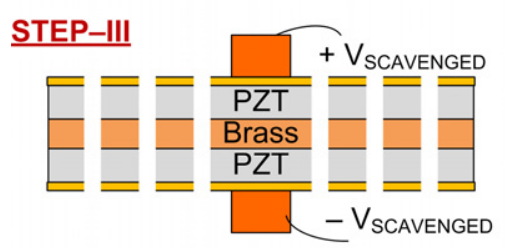

Cross-sectional Side View

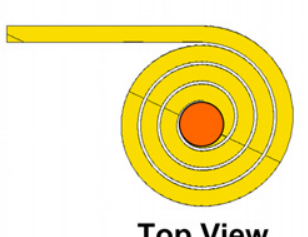

Top View
5-) Mounting on an electrically conductive mechanical support.

Figure 11. Fabrication process of spiral energy scavengers.

beam spot size is kept at $55 \mu \mathrm{m}$. The best etch profile is obtained using low laser fluence $\left(250 \mathrm{~mJ} \mathrm{~cm}^{-2}\right)$, close to the ablation threshold level, and utilizing low linear cutting velocity $\left(0.1 \mathrm{~mm} \mathrm{~s}^{-1}\right)$ for fewer passes (3-4 passes) over the same cutting path. Comparison of the femto-second laser cuts to our previous trials with an Nd:YAG nano-second laser $(\lambda=1064 \mathrm{~nm})$ shows that the first achieves straighter wall edges, minimum melt-zone and less damage to the material (figure 12).

\subsection{In vitro testing of the final prototypes}

Testing of the final prototypes is performed on a bench test setup shown in figure 13. A fabricated spiral beam is clamped at its center between two electrically conductive posts. These posts act as both mechanical supports and

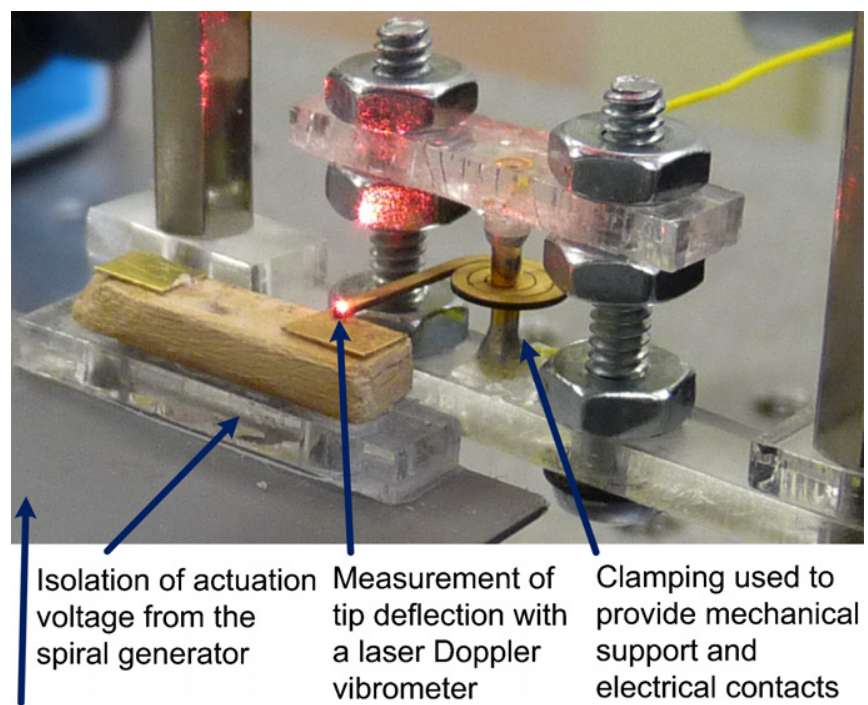

Piezoelectric actuator imitating wing flapping at $100 \mathrm{~Hz}$ with $0.8 \mathrm{~mm}-\mathrm{pp}$ deflection with a sinusoidal waveform

Figure 13. Setup used to test spiral generators with imitated wing flapping.

electrical connections. With the help of a micrometric positioner, the tip of the beam is placed in contact with a piezoelectric actuator, which is used to imitate the wing flapping of a Green June Beetle at $100 \mathrm{~Hz}$. The tip deflection of the spiral beam is measured via a laser Doppler vibrometer, and all power harvesting measurements are obtained at $0.8 \mathrm{~mm}_{\mathrm{pp}}$ deflection, which is the rated deflection of the beetle's elytra close to the wing base. The output of the generator is connected in series with a resistive load and a current meter. An average power of $18.5 \mu \mathrm{W}$ and $22.5 \mu \mathrm{W}$ are harvested from two spiral generators with different geometric designs (figure 14). Geometrical design variables, device specifications and test results of the final prototypes are summarized in table 3. Measurements indicate that $>45 \mu \mathrm{W}$ can be scavenged from a Green June Beetle's wing vibrations by deploying one spiral generator on each wing.

\section{Discussion}

Non-resonant vibration energy harvesting offers a lightweight and generic perpetual power solution for flight control systems
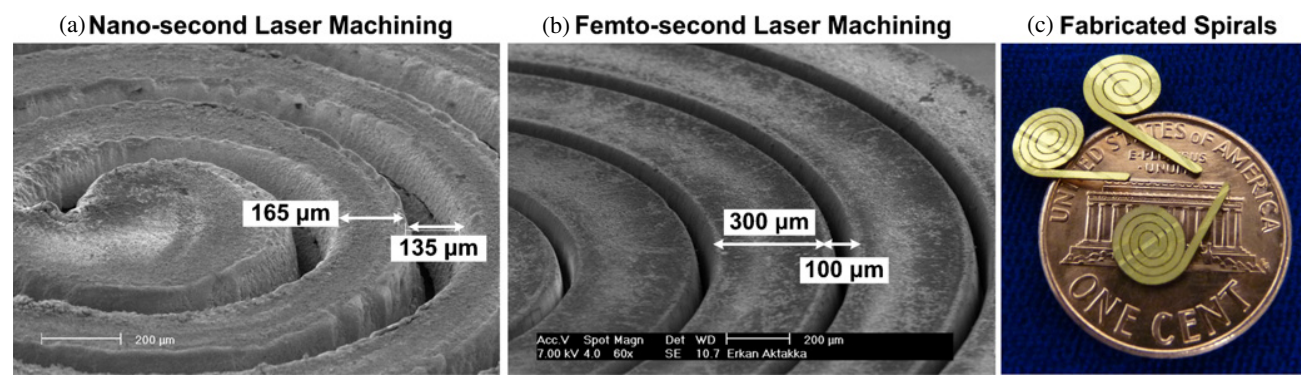

Figure 12. SEM images of spiral structures micro-machined with $(a)$ Nd:YAG nano-second laser, $(b)$ Ti-Sapphire femto-second laser and (c) spiral harvesters fabricated by femto-second laser. 
Table 3. Performance summary of spiral beam energy scavengers.

\begin{tabular}{|c|c|c|}
\hline $\begin{array}{l}\text { Generator } \\
\text { parameters }\end{array}$ & $\begin{array}{l}\text { Spiral beam } \\
\text { prototype-I }\end{array}$ & $\begin{array}{l}\text { Spiral beam } \\
\text { prototype-II }\end{array}$ \\
\hline \multicolumn{3}{|c|}{ Design variables } \\
\hline PZT thickness on each side & $130 \mu \mathrm{m}$ & $130 \mu \mathrm{m}$ \\
\hline Brass shim layer thickness & $130 \mu \mathrm{m}$ & $130 \mu \mathrm{m}$ \\
\hline Arm width & $550 \mu \mathrm{m}$ & $700 \mu \mathrm{m}$ \\
\hline Gap between turns & $100 \mu \mathrm{m}$ & $100 \mu \mathrm{m}$ \\
\hline Number of circular turns & 3.0 & 2.5 \\
\hline Radius of center clamp region & $750 \mu \mathrm{m}$ & $750 \mu \mathrm{m}$ \\
\hline Additional arm length & $6.5 \mathrm{~mm}$ & $8.5 \mathrm{~mm}$ \\
\hline \multicolumn{3}{|c|}{ Device specs } \\
\hline Spring constant (calculated) & $73.5 \mathrm{mN} \mathrm{mm}^{-1}$ & $72.6 \mathrm{mN} \mathrm{mm}^{-1}$ \\
\hline Force input from insect (calculated) & $29.4 \mathrm{mN}$ & $29.0 \mathrm{mN}$ \\
\hline Spiral die area & $6.3 \mathrm{~mm} \times 5.9 \mathrm{~mm}$ & $6.1 \mathrm{~mm} \times 5.7 \mathrm{~mm}$ \\
\hline Device volume & $10.2 \mathrm{~mm}^{3}$ & $11.5 \mathrm{~mm}^{3}$ \\
\hline Device weight & $81.6 \mathrm{mg}$ & $92.0 \mathrm{mg}$ \\
\hline \multicolumn{3}{|c|}{ Test results } \\
\hline Power output (1 spiral, at $100 \mathrm{~Hz}$ ) & $18.5 \mu \mathrm{W}$ & $22.5 \mu \mathrm{W}$ \\
\hline Optimum resistive load ( $\left.R_{\mathrm{LOAD}}\right)$ & $300 \mathrm{k} \Omega$ & $225 \mathrm{k} \Omega$ \\
\hline$V_{\mathrm{RMS}} \times I_{\mathrm{RMS}}\left(\right.$ on $R_{\mathrm{LOAD}}$, at $\left.100 \mathrm{~Hz}\right)$ & $2.36 \mathrm{~V} \times 7.86 \mu \mathrm{A}$ & $2.25 \mathrm{~V} \times 10.01 \mu \mathrm{A}$ \\
\hline Average power/volume $(85-105 \mathrm{~Hz})$ & $1.72 \mathrm{~mW} \mathrm{~cm}^{-3}$ & $1.86 \mathrm{~mW} \mathrm{~cm}^{-3}$ \\
\hline Average power/weight $(85-105 \mathrm{~Hz})$ & $216 \mu \mathrm{W} \mathrm{g}^{-1}$ & $233 \mu \mathrm{W} \mathrm{g}^{-1}$ \\
\hline
\end{tabular}

Table 4. Comparison of the presented work with other available energy harvesting methods.

\begin{tabular}{|c|c|c|c|c|c|}
\hline Ref. & Energy source & Transduction & Operating condition & Power density & Raw power \\
\hline This work & $\begin{array}{l}\text { Vibration (beetle } \\
\text { flight) }\end{array}$ & Piezoelectric (PZT spiral beams) & $\begin{array}{l}\text { Non-resonant (broadband) } \\
\text { (tested at } 85-105 \mathrm{~Hz} \text { ) }\end{array}$ & $233 \mu \mathrm{W} \mathrm{g}^{-1}$ & $45 \mu \mathrm{W}$ \\
\hline$[18]$ & $\begin{array}{l}\text { Vibration (moth } \\
\text { flight) }\end{array}$ & Electromagnetic (NdFeB magnets) & $\begin{array}{l}\text { Resonant (bandwidth }=1 \mathrm{~Hz} \text { ) } \\
\text { (tested at } 25.8 \mathrm{~Hz} \text { ) }\end{array}$ & $656 \mu \mathrm{W} \mathrm{g}^{-1}$ & $800 \mu \mathrm{W}$ \\
\hline$[28]^{\mathrm{a}}$ & $\begin{array}{l}\text { Solar }\left(1 \mathrm{~cm}^{2}\right. \\
\text { assumed solar } \\
\text { cell area })\end{array}$ & $\begin{array}{l}\text { Lightweight, flexible thin-film c-Si } \\
\text { with } 2 \%-15 \% \text { efficiency (efficiency } \\
\text { depends on illumination level) }\end{array}$ & $\begin{array}{l}\text { Usual daylight }\left(100 \mathrm{~W} \mathrm{~m}^{-2}\right) \\
\text { Overcast day }\left(10 \mathrm{~W} \mathrm{~m}^{-2}\right) \\
\text { Indoor office }\left(1 \mathrm{~W} \mathrm{~m}^{-2}\right)\end{array}$ & $\begin{array}{l}27450 \mu \mathrm{W} \mathrm{g}^{-1} \\
1960 \mu \mathrm{W} \mathrm{g}^{-1} \\
40 \mu \mathrm{W} \mathrm{g}^{-1}\end{array}$ & $\begin{array}{l}1400 \mu \mathrm{W} \\
100 \mu \mathrm{W} \\
2 \mu \mathrm{W}\end{array}$ \\
\hline$[17]$ & $\begin{array}{l}\text { Thermal (beetle } \\
\text { body heat) }\end{array}$ & $\mathrm{Bi}_{2} \mathrm{Te}_{3} / \mathrm{Sb}_{2} \mathrm{Te}_{3}$ thermocouples & $\begin{array}{l}11^{\circ} \mathrm{C} \text { temperature gradient } \\
\text { (available during flight) }\end{array}$ & $56 \mu \mathrm{W} \mathrm{g}^{-1}$ & $0.8 \mu \mathrm{W}$ \\
\hline
\end{tabular}

a Values estimated using data provided in [28].

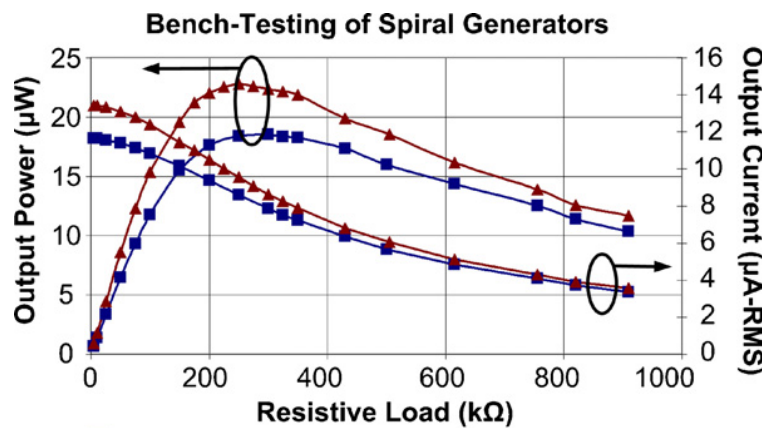

Final Prototype - I Final Prototype - II

Figure 14. Test results of the spiral generators.

deployed in cyborg insects. Direct coupling between the energy harvester and vibration source can eliminate the need for a large proof mass, a common drawback of resonant energy harvesters. The studied spiral generators weigh only $<0.2 \mathrm{~g}$, are not restricted to operate at a specific wing beat frequency, and can generate $>45 \mu \mathrm{W}$ during a Green June Beetle's flight. Compared to other available energy harvesting methods for

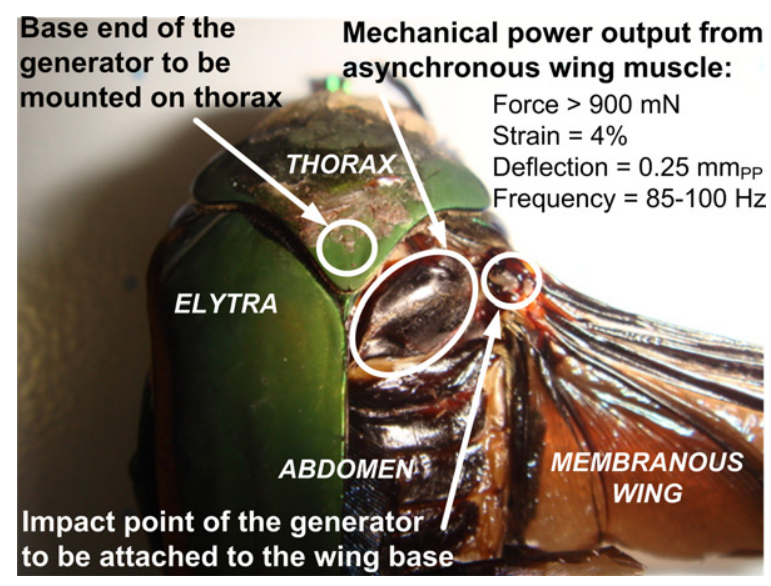

Figure 15. Conceptual device connection to the beetle's wing base.

hybrid insects, the presented work has the advantages of nonresonant operation and independence from the ambient light conditions (table 4). The output of the presented energy harvester can be further improved with a direct connection from the device's impact point to the wing base (figure 15), 
where the asynchronous flight muscle can supply up to $\sim 0.9 \mathrm{~N}$ [29]. Even though the peak-to-peak deflection is $\times 3$ lower at this point, a stiffer spiral beam design can take advantage of the high input force from the muscle to generate up to $\times 10$ more power output, sufficient to power a flight-control microsystem on a Green June Beetle [14].

\section{Conclusion}

In this paper, theoretical considerations for energy scavenging from a given vibration source are presented and optimization of a generator to harvest power from insect flight is described. After performing several measurements on a subject beetle, the optimum location for maximum power output is determined to be the flight muscle base, and harvesting of $\sim 115 \mu \mathrm{W}$ from this location is demonstrated with a meso-scale piezoelectric beam. Using back-pack style energy scavenger prototypes, piezoelectric cantilever beams are mounted on a beetle at different locations, and are able to generate 11.5 and $7.5 \mu \mathrm{W}$ during tethered flight. In order to provide a lower spring constant in a smaller area, a piezoelectric spiral beam is designed and fabricated via laser machining. In vitro testing of this final prototype shows $>45 \mu \mathrm{W}$ total output delivered from two spirals, at the rated deflection and frequency of the subject beetle's wing strokes.

\section{Acknowledgments}

This work was supported by the Hybrid Insect MEMS program of DARPA under grant no N66001-07-1-2006. The facilities used for this research include the Lurie Nanofabrication Facility (LNF) at the University of Michigan. The authors thank Dr Becky Peterson for assistance in preparing the manuscript.

\section{References}

[1] Wood R 2008 Fly, robot, fly IEEE Spectr. 45 25-9

[2] van Breugel F, Regan W and Lipson H 2008 From insects to machines IEEE Robot. Autom. Mag. 14 68-74

[3] Ruijsink R, Remes B, de Wagter C and de Croon G 2008 Delfly micro specificities Delft University of Technology http://www.delfly.nl

[4] Michelson R C and Naqvi M A 2003 Extraterrestrial flight (Entomopter-based Mars surveyor) von Karman Institute for Fluid Dynamics RTO/AVT Lecture Series on Low Reynolds Number Aerodynamics on Aircraft Including Applications in Emerging UAV Technology; http://angel-strike. com/entomopter/MICHELSON-NAQVI-2.pdf

[5] Talwar S K, Xu S, Hawley E S, Weiss S A, Moxon K A and Chapin J K 2002 Rat navigation guided by remote control Nature 417 37-8

[6] The Ministry of Science and Technology of People's Republic of China 2007 Robotized bird China Science and Technology Newsletter vol 468

[7] Brown S 2006 Stealth sharks to patrol the high seas New Scientist Magazine Issue vol 2541 p 30

[8] Moore T E, Crary S B, Koditschek D E and Conklin T A 1998 Directed locomotion in cockroaches: biobots Acta Entomologica Slovenica 6 71-8
[9] Visvanathan K, Gupta N K, Maharbiz M M and Gianchandani Y 2008 Flight initiation and direction control of beetles by microthermal stimulation Proc. 13th IEEE Solid-State Sensor, Actuator, and Microsystems Workshop (Hilton Head '08) pp 126-9

[10] Tsang W M, Aldworth Z, Stone A, Permar A, Levine R, Hildebrand J G, Daniel T, Akinwande A I and Voldman J 2008 Insect flight control by neural stimulation of pupae-implanted flexible multisite electrodes 12th Int. Conf. on Miniaturized Systems for Chemistry and Life Sciences pp 1922-4

[11] Bozkurt A, Paul A, Pulla S, Ramkumar A, Blossey B, Ewer J, Gilomur R and Lal A 2007 Microprobe microsystem platform inserted during early metamorphosis to actuate flight muscle Proc. IEEE Int. Conf. on Micro Electro Mechanical Systems (MEMS 2007) pp 405-8

[12] Bozkurt A, Gilmour R, Stern D and Lal A 2008 MEMS based bioelectronic neuromuscular interfaces for insect cyborg flight control Proc. IEEE Int. Conf. on Micro Electro Mechanical Systems (MEMS 2008) pp 160-3

[13] Bozkurt A, Lal A and Gilmour R 2008 Electrical endogenous heating of insect muscles for flight control 30th IEEE Int. Conf. on Engineering in Medicine and Biology Society (EMBS 2008) pp 5786-9

[14] Sato H, Berry C W, Casey B E, Lavella G, Yao Y, Vanderbrooks J M and Maharbiz M M 2008 A cyborg beetle: insect flight control through an implantable, tetherless microsystem Proc. IEEE Int. Conf. on Micro Electro Mechanical Systems (MEMS 2008) pp 164-7

[15] Aktakka E E, Kim H, Atashbar M Z and Najafi K 2008 Mechanical energy scavenging from a cyborg insect Proc. 13th IEEE Solid-State Sensor, Actuator, and Microsystems Workshop (Hilton Head 08) pp 382-3

[16] Reismann T and Garcia E 2008 An ultra-lightweight multi-source power harvesting system for insect cyborg sentinels ASME Conf. on Smart Materials, Adaptive Structures and Intelligent Systems SMASIS 2008 p 662

[17] Ghafouri N, Kim H, Atashbar M Z and Najafi K 2008 A micro thermoelectric energy scavenger for a hybrid insect Proc. 7th IEEE Int. Conf. on Sensors (Sensors 2008) pp 1249-52

[18] Chang S C, Yaul F M, Dominguez-Garcia A, O'Sullivan F, Otten D M and Lang J H 2009 Harvesting energy from moth vibrations during flight 9th Int. Workshop on Micro and Nanotechnology for Power Generation and Energy Conversion Applications (PowerMEMS 2009) pp 57-60

[19] Sane S P and Jacobson N P 2006 Induced airflow in flying insects II-measurement of induced flow J. Exp. Biol. 209 43-56

[20] Stevenson R D and Josephson R K 1990 Effects of operating frequency and temperature on mechanical power output from moth flight muscle J. Exp. Biol. 149 61-78

[21] Farnworth E G 1972 Effects of ambient temperature, humidity, and age on wing-beat frequency of periplaneta species J. Insect Physiol. 18 827-39

[22] Atkins M D 1960 A study of the flight of the Douglas-fir beetle Dendroctonus pseudolsugae Hopk. (Coleoptera: Scolytidae) II. Flight movements Can. Entomologist 92 941-54

[23] Josephson R K, Malamud J G and Stokes D R 2001 The efficiency of an asynchronous flight muscle from a beetle J. Exp. Biol. 204 4125-39

[24] Roundy S J 2003 Energy scavenging for wireless sensor nodes with a focus on vibration to electricity conversion $P h D$ Dissertation University of California at Berkeley

[25] Roundy S, Wright P K and Rabaey J 2003 A study of low level vibrations as a power source for wireless sensor nodes Comput. Commun. 26 1131-44 
[26] Josephson R K, Malamud J G and Stokes D R 2000

Asynchronous muscle: a primer J. Exp. Biol. 203 2713-22

[27] Piezo Systems Inc. 2008 Piezoceramic materials \& properties Piezo Systems Inc. Catalog no 7C 24-26

http://www.piezo.com/prodmaterialprop.html
[28] Schubert M B and Werner J H 2006 Flexible solar cells for clothing Mater. Today 9 42-50

[29] Askew G N and Marsh R L 2002 Muscle designed for maximum short-term power output: quail flight muscle J. Exp. Biol. 205 2153-60 